\title{
Islanding detection in three-phase and single-phase systems using pulsating high frequency signal injection
}

\author{
David Reigosa, Member, IEEE, Fernando Briz, Senior Member, IEEE, Cristian Blanco, Member, IEEE, Juan Manuel \\ Guerrero, Member, IEEE \\ University of Oviedo. Dept. of Elect., Computer \& System Engineering, Gijón, 33204, Spain. \\ diazdavid@,uniovi.es, fernando@isa.uniovi.es, blancocristian@uniovi.es, guerrero@isa.uniovi.es
}

\begin{abstract}
This paper analyzes the use of pulsating high frequency signal injection for islanding detection purposes. Active islanding detection using high frequency signal injection is an appealing option due to its reduced non-detection zone, reduced cost and ease of implementation. The use of a rotating high frequency signal has been reported and analyzed. However, this method can only be applied to three-phase systems. In this paper, the use of a pulsating high frequency signal injection is proposed. While it uses the same principles as rotating signal injection, it can be applied to both threephase and single-phase systems. ${ }^{1}$
\end{abstract}

\section{Introduction}

Islanding is defined as the situation where a distributed generator (DG) or DGs continue generating power when they are not connected to the utility grid. Islanding detection has been the focus of significant research efforts during the last years due to the increasing share of the distributed generation in the power system. Distributed generation can be based either on renewable (wind turbines, photovoltaic, ...) and non-renewable (biomass, fuel cells, micro-gas turbines,...) energy resources. National, regional and local authorities regulate the interconnection of the distributed energy resources to the utility grid, in most of the cases following the standards and recommendation that are published by standardizing institutions [1-8]. In all the cases the standards require that the system has to detect if it is connected or disconnected from the utility grid (islanding detection) within a timeframe, e.g. 2 seconds for the IEEE1547 [1], UL-1741 [2], IEC-62116 [3], AS-4777 [4], IEEE929 [5] and DIN-VDE-0126 [6], or 5 seconds for the Swiss [7] and Australian [8] standards. These standards use the impedance variation within the considered timeframe as the metric for islanding detection, e.g. $1 \Omega$ variation for the German and $0.5 \Omega$ for the Swiss and Australian.

Three different scenarios can be considered for islanding detection: Single-inverter, Multi-inverter and Microgrid [9]. In the Single-inverter scenario only one DG exists and all the power is exported to the grid. In the Multi-inverter scenario most (or all) of the power generated by the DGs is exported to the grid throughout the point of common coupling (PCC). In the Microgrid scenario, a major portion (or all) of power generated by the DGs is consumed by the microgrid loads, the remaining power being exported to the grid throughout the PCC. The Multi-inverter case could be considered as a particular case of the Microgrid scenario, but with a major portion of the energy being exported to the utility grid. In all cases, the system is required to have the ability to detect if it is connected or isolated from the utility grid [9, 17-19].

Islanding detection methods can be classified into three groups: passive $[10,11,22,25,29]$, active [9, 11-19, 23, 24, $26,27,28]$ and communication based [11] methods. Passive

1 This work was supported in part by the Research, Technological Development and Innovation Programs of the Ministry of Science and Innovation under grant MICINN-10-CSD2009-00046 and by the Personnel Research Training Program funded by the Regional Ministry of Education and Science of the Principality of Asturias under grant BP11-107. and active methods are inverter resident $[9,10]$, while communication based methods are remote $[9,10]$. Passive based methods are grid friendly, as they do not introduce any disturbance in the grid [10], but have the disadvantage of a large non-detection-zone (NDZ) [11]. Active methods are based on the injection of some disturbing signal in the grid [9, 11-19], therefore having a negative impact on the power quality. However, they have low NDZ $[17,18]$, being easy and cheap to implement. Finally, communication based methods have no NDZ, but they need a communication infrastructure, being therefore subjected to communication failures [10, 17, 18].

Active islanding detection based methods can be further divided into two groups:

- Grid variable variation based methods [11]. Islanding is detected from the grid response to a small disturbance, typically in the voltage or frequency, produced by the power converter connecting the DG to the microgrid.

- Impedance estimation based methods [11-19]. In these methods, islanding is detected from variations at the power converter output impedance. These methods can be further divided into methods that estimate the impedance by the variation of the active/reactive power [12] or by the injection of some form of high frequency excitation [13-18]. The high frequency excitation can be injected continuously or intermittently $[17,18]$. The use of harmonics due to the non-ideal behavior of PWM inverters has also been recently proposed to estimate the high frequency impedance [19], no high frequency signal being injected in this case. It is noted that the methods reported in [12-19] can only be used in three-phase systems.

While the implementation of islanding active method based on the high frequency impedance variation is relatively simple in the case of Single-inverter, interference among converters can occur both in the Multi-inverter and Microgrid scenarios, which can result in erroneous impedance estimation and therefore incorrect islanding detection [9, 17, 18]. Strategies to prevent from this to happen have already been proposed $[9,18]$.

Most of the impedance estimation active islanding detection methods that have been proposed are intended for three-phase systems [11-18]. Nevertheless, single-phase DGs (e.g. single-phase micro-wind generation, small-scale solar panel,...) for low-power home applications are becoming of great interest. The reduced implementation cost of the active islanding detection based methods therefore makes them an appealing option for these kinds of applications.

In this paper, islanding detection using a pulsating high frequency signal is proposed. The main advantage of the pulsating excitation compared to other forms of high frequency excitations that have already been proposed [12$19]$ is that it can be used indistinctly with single-phase and 
three-phase systems, while methods in [12-19] can only be used in three-phase systems. Compared to intermittent injection methods $[12,13,15]$, the proposed method allows almost instantaneous detection of island/grid-connected condition, as it uses continuous injection. Contrary to this, with intermittent injection $[12,13,15]$ detection of island/grid-connected condition is only possible when the high frequency signal is injected, further restriction for these methods come from the fact that a time delay in the processing of the signals is needed due to the transient in the resulting high frequency currents whenever the high frequency voltage is injected [17]. Regardless of implementation aspects, the proposed method responds to the same principles as continuous rotating high frequency voltage signal injection based islanding detection methods [17-19], and provides therefore similar performance in terms of accuracy and reliability detecting the island/grid condition in three-phase systems.

An additional advantage of the pulsating high frequency signal injection is that this type of excitation can be used for unbalance fault detection in three-phase systems.

The paper is organized as follows. A brief review of active islanding detection methods based on high frequency signal injection as well as the analytical formulation of the proposed method is presented in section II. The use of pulsating high frequency signal injection for phase-to-phase and phase-to-ground fault detection in three-phase systems is discussed in Section III. Finally simulation and experimental results confirming the viability of the method are shown in section IV and V respectively.

\section{Islanding detection using pulsating high frequency signal injection}

DGs are usually connected to the main grid/microgrid by means of a three-phase (see Fig. 1a) or single-phase (see Fig. 1b) PWM-VSI [17-20]. The H-bridge inverter (Fig. 1b) is the most common topology in single-phase systems [20]. High frequency signal injection active islanding detection based methods inject a high frequency signal superposed on the fundamental voltage through the PWM-VSIs, islanding being detected from the variations of the measured high frequency impedance. The use of a rotating high frequency signal has been proposed for islanding detection [9, 17-19]; however this type of high frequency excitation cannot be applied to single-phase systems.

Selection of the frequency for the high frequency excitation involves trading off several issues, including the adverse impact of the injected signal on the power quality, the spectral separation with the fundamental voltage as well as with the output LCL filter and the grid resonance frequencies [17, 18]. Frequencies ranging between 75 and $400 \mathrm{~Hz}$ can be found in the literature [9, 11-19].

The principles and implementation of the proposed islanding detection method using a pulsating high frequency signal are analyzed following. In the first place, the case of three-phase system is considered, the single-phase case being analyzed later.

a) Three-phase systems

When a pulsating high frequency signal voltage (1) is injected into a three-phase system with an angle of injection $\varphi_{i}$, the resulting high frequency current at the output of the LCL filter (see Fig. 1) is given by (2), the grid high frequency impedance being (3), where $v_{d q h f}$ is the injected high frequency voltage complex vector, $V_{h f}$ is the magnitude of the injected high frequency signal, $\omega_{h f}$ is the frequency of the high frequency signal, $v_{\text {dqughf }}$ is the output LCL filter high frequency voltage complex vector, $i_{d q \mu g h f}$ is the output LCL filter high frequency current complex vector, $i_{d q h f}$ is the output inverter high frequency current complex vector, $L_{l}$ is the inverter side LCL filter inductance, $L_{2}$ is the grid side LCL filter inductance, $Z_{\text {dqughf }}$ is the microgrid high frequency impedance and $\varphi_{Z}$ is the phase of the microgrid high frequency impedance. The transformation from three-phase to $d q 0$ quantities is given by (4). The angle of injection $\varphi_{i}$ can be selected to be constant, or can change with an angular frequency of $\omega_{i}$. In the first case, the pulsating signal will be injected in a stationary reference frame, while in the second case, the pulsating signal is in injected in a reference frame that rotates at $\omega_{i}$.

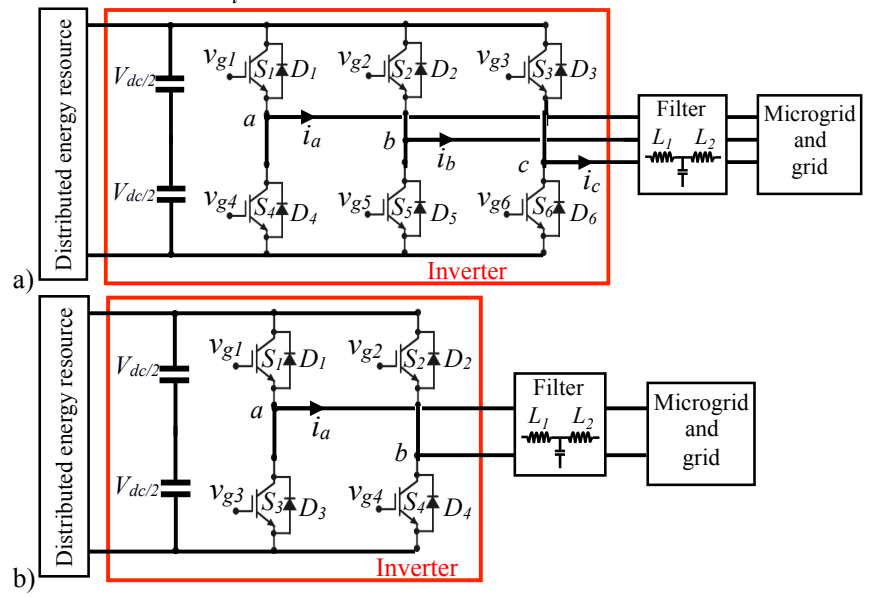

Fig 1. Simplified distributed energy resource connection to the utility grid/microgrid using a) a three-phase VSI, and b) a single-phase VSI.

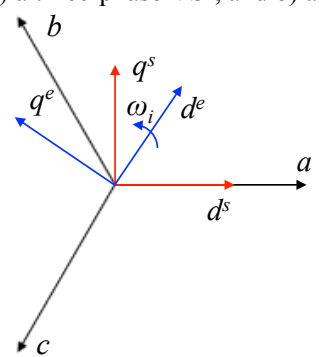

Fig. $2 a b c$ and $d q$ reference systems. $d q_{s}=$ stationary reference frame, $d q_{e}=$ rotating reference frame

It is observed from (1)-(2) that the pulsating high frequency voltage and current can be decomposed into two rotating signals $\left(v_{d q h f}^{p c}, v_{d q h f}^{n c}, i_{d q h f}^{p c}, i_{d q h f}^{n c}\right)$ which rotate in opposite direction, each of half the amplitude of the injected signal. Both components can potentially be used for high frequency impedance estimation (3).

$$
\begin{aligned}
v_{d q h f}^{e} & =V_{h f} \cos \left(\omega_{h f} t\right) e^{j \varphi_{i}}=V_{h f} \cos \left(\omega_{h f} t\right) e^{j \omega_{i} t}= \\
& =\frac{V_{h f}}{2} e^{j\left(\omega_{h f}+\omega_{i}\right) t}+\frac{V_{h f}}{2} e^{j\left(-\omega_{h f}+\omega_{i}\right) t}=v_{d q h f}^{p c}+v_{d q h f}^{n c}
\end{aligned}
$$




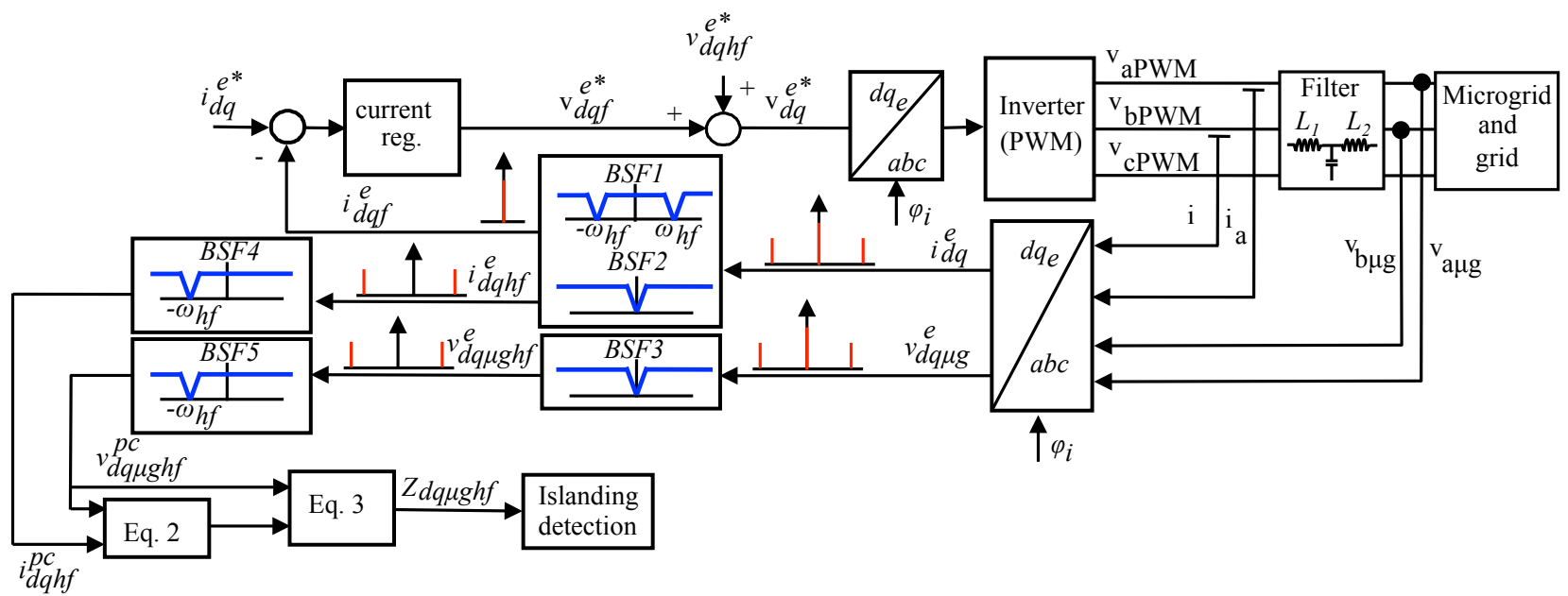

Fig 3. Signal processing for islanding detection using a three-phase inverter.

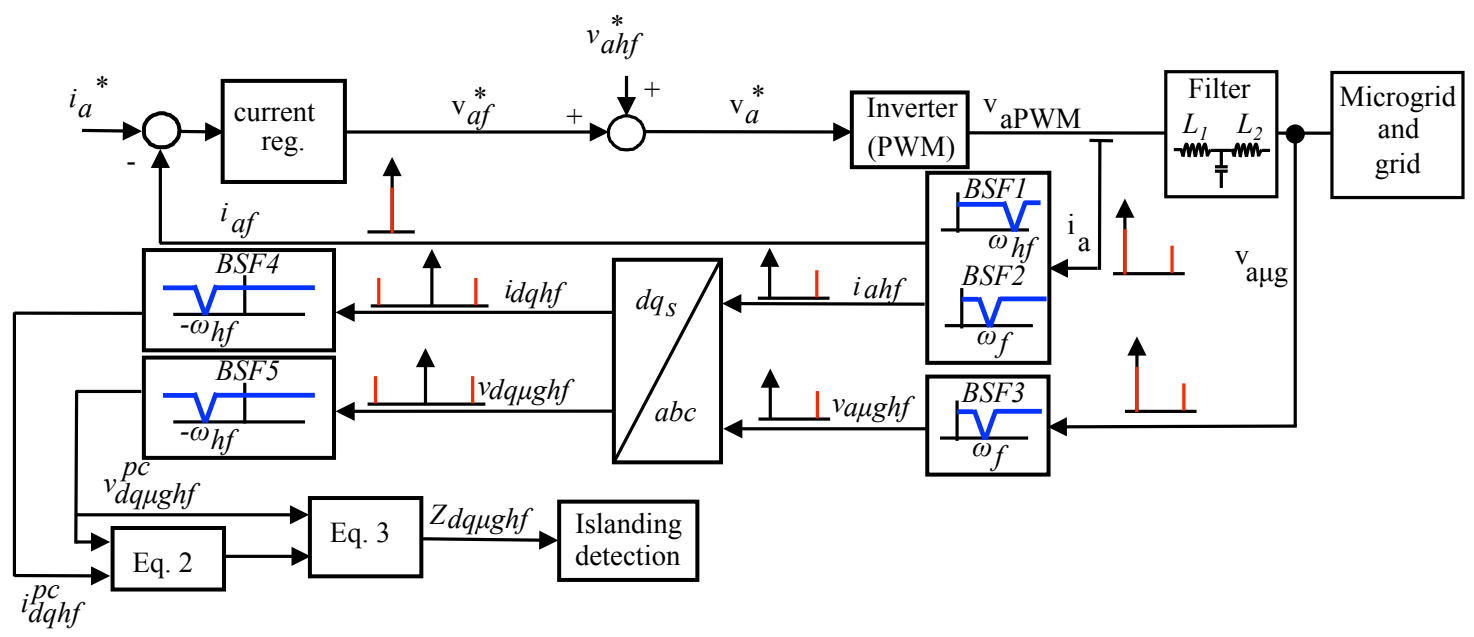

Fig 4. Signal processing for islanding detection using a single-phase inverter.

$$
\begin{aligned}
i_{d q \mu g h f}^{e} & =\frac{v_{d q h f}^{e}-v_{d q \mu g h f}^{e}-j \omega_{h f} L_{1} i_{d q h f}^{e}}{j \omega_{h f} L_{2}}= \\
& =\frac{V_{h f}}{2 *\left|Z_{d q \mu g h f}\right|} e^{j\left(\left(\omega_{h f}+\omega_{i}\right) t-\varphi_{Z}\right)}+\frac{V_{h f}}{2 *\left|Z_{d q \mu g h f}\right|} e^{j\left(\left(-\omega_{h f}+\omega_{i}\right) t+\varphi_{Z}\right)}= \\
& =i_{d q \mu g h f}^{p c}+i_{d q \mu g h f}^{n c}
\end{aligned}
$$$$
Z_{d q h f \mu g}=\frac{v_{d q \mu g h f}^{p c}}{i_{d q \mu h h f}^{p c}}=\frac{v_{d q \mu g h f}^{n c}}{i_{d q \mu g h f}^{n c}}
$$

$$
\begin{gathered}
=\frac{e^{j\left(\left(\omega_{h f}+\omega_{i}\right) t\right)} V_{h f} / 2}{e^{j\left(\left(\omega_{h f}+\omega_{i}\right) t-\varphi_{Z}\right)} * V_{h f} / 2 *\left|Z_{d q \mu g h f}\right|}= \\
=\frac{e^{j\left(\left(-\omega_{h f}+\omega_{i}\right) t\right)} V_{h f} / 2}{e^{j\left(\left(-\omega_{h f}+\omega_{i}\right) t+\varphi_{Z}\right)} * V_{h f} / 2 *\left|Z_{d q \mu g h f}\right|}
\end{gathered}
$$$$
f_{d q}^{e}=2 / 3\left(f_{a}+f_{b} e^{j * 2 * \pi / 3}+f_{c} e^{j^{* * *} \pi / 3}\right) e^{-j^{*} \varphi_{i}}=
$$$$
=2 / 3\left(f_{a}+f_{b} e^{j * 2 * \pi / 3}+f_{c} e^{j^{*} 4 * \pi / 3}\right) e^{-j^{*} \omega_{i} t}=f_{d q}^{s} e^{-j^{*} \omega_{i} t}
$$

neutral wire is not typically available in the connection of three-phase distributed energy resources to the utility grid/microgrid through three-phase VSI (see Fig. 1a). Therefore the zero sequence component of the current (4) is always zero in the inverter side.

The pulsating high frequency signal can be injected either in a stationary reference frame $\left(\omega_{i}=0\right.$ in (1), see $d q_{s}$ in Fig. 2) or in a rotating reference frame $\left(\omega_{i} \neq 0\right.$ in (1), see $d q_{e}$ in Fig. 2). When the high frequency signal is injected in a reference frame that rotates e.g. aligned with the $d_{e}$ or $q_{e}$ axis (see Fig. 2), all the phases are excited sequentially, meaning that the high frequency impedance of all the three phases can be measured. On the contrary, if the high frequency signal is injected in a stationary reference frame, one, two or all the three phases can be excited, depending on the angle of injection selected. As an example, only phase $a$ is excited if the signal is injected in the $d_{s}$ axis, (see Fig. 2), in this case the high frequency signal will be sensitive only to phase $a$ condition. It is also noted that since the connection/disconnection between the microgrid and the grid occurs simultaneously in all the three phases, the number of phases being excited would be irrelevant for islanding detection, i.e. all the three phases reflect the island/grid transitions. However, sequential excitation of all phases opens interesting possibilities for detecting asymmetric faults in three phase systems. This issue will be discussed in detail in section III.

of the loads are connected to ground, which is the case for low voltage public distribution systems [22]. However, the 
Fig. 3 shows the signal processing needed for islanding detection using a pulsating high frequency signal for the case of a three-phase system. In the implementation shown in Fig. 3 the PWM-VSI is current regulated, a synchronous PI current regulator being used for this purpose ("Current reg." block in Fig. 3). In this case, the current regulator can react against the induced high frequency current. To prevent this, band-stop filters are used to reject the positive and negative sequence current components (2) from the current feedback (BSF1 in Fig. 3). Band-stop filters $B S F 2$ and $B S F 3$ in Fig. 3 are used to reject the fundamental component of the voltage and current respectively, while BSF4 and BSF5 reject the negative sequence components, the positive sequence component of these signals being finally obtained. The high frequency impedance is obtained using (2) and (3), islanding being detected from the high frequency impedance variation.

\section{b) Single-phase system}

Though the concept of complex vector defined by (4) is only valid in principle for the case of three-phase systems, it is also possible to use it with single-phase systems. This can be done by defining a complex vector in which one of the components (e.g. $d$-axis in (5) and (6)) is made equal to the corresponding single-phase voltage/current and the other component (e.g. $q$-axis in (5) and (6)) is made equal to zero. By doing this, the high frequency impedance (3) in a singlephase system can be estimated from (5) and (6), where $v_{\text {ahf }}$ is the injected high frequency phase voltage, $v_{a \mu g h f}$ and $i_{\text {aughf }}$ are the filter high frequency output phase voltage and current respectively and $i_{a h f}$ is the inverter high frequency output phase current.

$$
\begin{aligned}
v_{d q h f} & =\left[\begin{array}{c}
v_{a h f} \\
0
\end{array}\right]=\left[\begin{array}{c}
V_{h f} \cos \left(\omega_{h f} t\right) \\
0
\end{array}\right]= \\
& =\frac{V_{h f}}{2} e^{j \omega_{h f t} t}+\frac{V_{h f}}{2} e^{-j \omega_{h f} t}=v_{d q h f}^{p c}+v_{d q h f}^{n c} \\
i_{d q \mu g h f} & =\left[\begin{array}{c}
i_{a \mu g h f} \\
0
\end{array}\right]=\left[\begin{array}{c}
\frac{v_{a h f}-v_{a \mu g h f}-j \omega_{h f} L_{1} i_{a h f}}{j \omega_{h f} L_{2}} \\
0
\end{array}\right]= \\
& =\frac{V_{h f}}{2 *\left|Z_{d q \mu g h f}\right|} e^{j\left(\omega_{h f} t-\varphi_{Z}\right)}+\frac{V_{h f}}{2 *\left|Z_{d q \mu g h f}\right|} e^{j\left(-\omega_{h f} t+\varphi_{Z}\right)}= \\
& =i_{d q \mu g h f}^{p c}+i_{d q u g h f}^{n c}
\end{aligned}
$$

Fig. 4 shows the signal processing needed for islanding detection in a single-phase system. A single band-stop filter is needed to reject the component at $\omega_{h f}$ (BSF1, see Fig. 4) to prevent the fundamental current regulator reaction. As for the three-phase system case, band-stop filters $B S F 2$ and $B S F 3$ reject the fundamental components and BSF4 and $B S F 5$ reject the negative sequence components. Once the positive sequence component of the voltage and current are isolated, the high frequency impedance is obtained using (2) and (3), islanding being detected from the high frequency impedance variation.

It is finally noted that though in all the discussion presented in this paper it is assumed that a high frequency voltage is injected, it is possible to combine high frequency voltage injection and high frequency current injection as

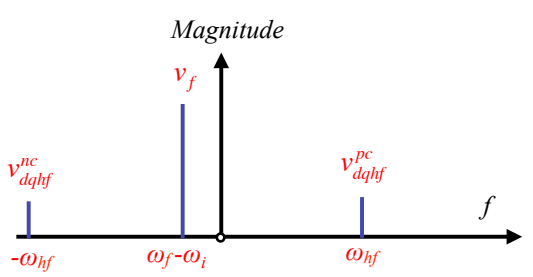

a)

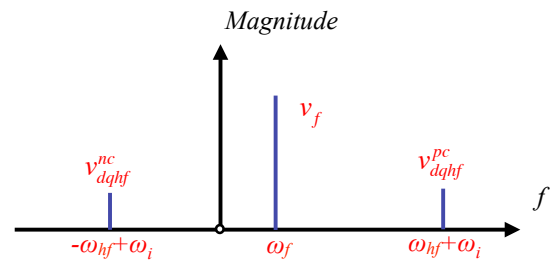

b)

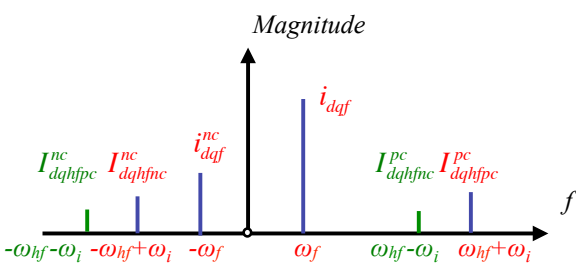

Fig. 5. a) PCC voltage vector spectrum in a rotating reference frame and b) in a stationary reference frame. c) Output inverter current vector spectrum when feeding a non-symmetrical load.

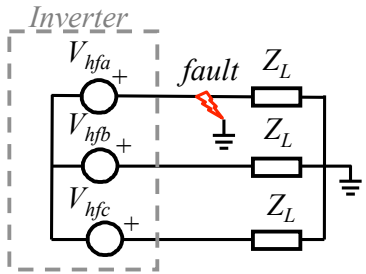

Fig. 6. a) Phase-to-ground fault, and b) phase-to-phase fault.

described in [9]. These can be advantageous when multiple parallel-connected inverters implement the method [9]. It is also noted that the dead-time effect in PWM single-phase inverters produces a distortion that can be expressed as (7) [19], being therefore possible to use any of the high order harmonics in (7) for islanding detection purposes [19].

$$
v_{a n}=\frac{4 \Delta V}{\pi} \sum_{n=1,5,7, \ldots} \frac{1}{n} \sin \left(n \omega_{f} t\right)
$$

\section{Phase-to-phase and phase-to-ground fault detection using pulsating high frequency signal injection}

It has already been mentioned that since islanding in three-phase systems occurs simultaneously in all the three phases, it can be readily detected independent of the high frequency signal injection mode, i.e. stationary or rotating. It is noted in this regard that the implementation of the injection in the stationary reference frame is slightly simpler. However, the injection of the high frequency signal in a rotating reference frame opens interesting possibilities for the detection of phase-to-phase and phase-to-ground faults in three-phase systems.

Fig. 5a and 5b show the PCC voltage vector spectrum in a rotating reference frame $\left(d q_{e}\right.$ in Fig. 2$)$ and in a stationary reference frame ( $d q_{s}$ in Fig. 2), when the pulsating high frequency voltage is been superimposed on top of the fundamental excitation. As shown in Fig. 5a, the pulsating high frequency signal can be decomposed in two rotating signals, $v_{d q h f}^{p c}$ and $v_{d q h f}^{n c}$ of frequencies $\omega_{h f}$ and $-\omega_{h f}$ 
respectively. By transforming this voltage vector to the stationary reference frame (see Fig. 5b), the frequency components $v_{d q h f}^{p c}$ and $v_{d q h f}^{n c}$ at $\omega_{h f}+\omega_{i}$ and $-\omega_{h f}+\omega_{i}$ are obtained respectively.

The most typical asymmetric faults that occur in threephase systems are the phase-to-ground, phase-to-phase and phase-to-neutral [21]. Typically the neutral wire is not available in the connection of three-phase distributed energy resources to the utility grid/microgrid through three-phase VSI (see Fig. 1a). Therefore, only the phase-to-ground and phase-to-phase faults will be analyzed in this section.

a) Phase-to-ground fault

When a pulsating voltage vector is injected into a threephase system with a fault to ground in phase $a$ (see Fig. 6a), the resulting high frequency phase currents are given by (8). The pulsating signal is injected in a $d q_{e}$ reference frame which rotates at $\omega_{i}=50 \mathrm{~Hz}$ and it is assumed that the fault impedance is much lower than the system (load) impedance $\left(Z_{L}\right)$.

$$
\left[\begin{array}{c}
i_{a} \\
i_{b} \\
i_{c}
\end{array}\right]=\left[\begin{array}{c}
\frac{V_{a} 3}{Z_{L}} e^{j\left(\left(\omega_{h f}+\omega_{i}\right) t-\varphi_{Z_{L}}\right)} \\
\frac{V_{b} \sqrt{3}}{Z_{L}} e^{j\left(\left(\omega_{h f}+\omega_{i}\right) t-5 * \pi / 6-\varphi_{Z_{L}}\right)} \\
\frac{V_{c} \sqrt{3}}{Z_{L}} e^{j\left(\left(\omega_{h f}+\omega_{i}\right) t+5 * \pi / 6-\varphi_{Z_{L}}\right)}
\end{array}\right]+\left[\begin{array}{c}
\frac{V_{a} 3}{Z_{L}} e^{j\left(\left(-\omega_{h f}+\omega_{i}\right) t+\varphi_{Z_{L}}\right)} \\
\frac{V_{b} \sqrt{3}}{Z_{L}} e^{j\left(\left(-\omega_{h f}+\omega_{i}\right) t+5 * \pi / 6+\varphi_{Z_{L}}\right)} \\
\frac{V_{c} \sqrt{3}}{Z_{L}} e^{j\left(\left(-\omega_{h f}+\omega_{i}\right) t-5 * \pi / 6+\varphi_{Z_{L}}\right)}
\end{array}\right.
$$

Applying Fortescue's theorem, (9), to the components in (8) at $\omega_{h f}+\omega_{i}$, a set of symmetrical components is obtained (10), with $i_{d a h f v c}^{0}, i_{d a h f p c}^{p c}$ and $i_{d a h f o c}^{n c}$ being the zero, positive and negative sequence components respectively. It is noted that though the same transformation could be used with the components in (8) at $-\omega_{h f}+\omega_{i}$, the discussion following focuses only for the frequency components at $\omega_{h f}+\omega_{i}$.

$$
\begin{aligned}
& {\left[\begin{array}{c}
i^{0} \\
i^{+} \\
i^{-}
\end{array}\right]=\left[\begin{array}{ccc}
1 & 1 & 1 \\
1 & a & a^{2} \\
1 & a^{2} & a
\end{array}\right] *\left[\begin{array}{c}
i_{a} \\
i_{b} \\
i_{c}
\end{array}\right]} \\
& {\left[\begin{array}{c}
i_{d q h f p c}^{0} \\
i_{d q h p c}^{p c} \\
i_{d q h f p c}^{n c}
\end{array}\right]=\left[\begin{array}{l}
\frac{2 \sqrt{3}}{3} I_{c c} e^{j\left(\left(\omega_{h f}+\omega_{i}\right) t-\varphi_{Z_{L}}\right)} \\
\frac{\sqrt{3}}{3} I_{c c} e^{j\left(\left(-\omega_{h f}-\omega_{i}\right) t-\varphi_{Z_{L}}\right)}
\end{array}\right]}
\end{aligned}
$$

where $I_{c c}=V_{b} \sqrt{3} / Z_{L}$.

If the fault occurs in phase $b$, the resulting symmetrical components using (9) are given by (11), while if the fault occurs in phase $c$ it is expressed by (12). It is observed from (10)-(12) that the faulty phase can be detected from the phase angle between the positive sequence component ( $\left.i_{d q h f p c}^{p c}\right)$ and the negative sequence component $\left(i_{d q h f p c}^{n c}\right)$, which is 0 when the faulty phase is phase $a, 2 \pi / 3$ when the faulty phase is phase $b$ and $4 \pi / 3$ when the faulty phase is phase $c$.

$$
\begin{aligned}
& {\left[\begin{array}{c}
i_{d q h f p c}^{0} \\
i_{d q h f p c}^{p c} \\
i_{d q h f p c}^{n c}
\end{array}\right]=\left[\begin{array}{c}
0 \\
\frac{2 \sqrt{3}}{3} I_{c c} e^{j\left(\left(\omega_{h f}+\omega_{i}\right) t-\varphi_{Z_{L}}\right)} \\
\frac{\sqrt{3}}{3} I_{c c} e^{j\left(\left(-\omega_{h f}-\omega_{i}\right) t+2 \pi / 3-\varphi_{Z_{L}}\right)}
\end{array}\right]} \\
& {\left[\begin{array}{c}
i_{d q h f p c}^{0} \\
i_{d q h f p c}^{p c} \\
i_{d q h f p c}^{n c}
\end{array}\right]=\left[\begin{array}{c}
\frac{2 \sqrt{3}}{3} I_{c c} e^{j\left(\left(\omega_{h f}+\omega_{i}\right) t-\varphi_{Z_{L}}\right)} \\
\frac{\sqrt{3}}{3} I_{c c} e^{j\left(\left(-\omega_{h f}-\omega_{i}\right) t+4 \pi / 3-\varphi_{Z_{L}}\right)}
\end{array}\right]}
\end{aligned}
$$

b) Phase-to-phase fault

When a pulsating voltage vector which rotates at $\omega_{i}$, is injected into a three-phase system in which a phase-to-phase fault between phases $a-b$ occurs (see Fig. 6b), the resulting phase currents are expressed by (13) and the resulting symmetrical components are given by (14) (only the phasors for the frequency components at $\omega_{h f}+\omega_{i}$ are shown). It is assumed that the fault impedance $\left(Z_{F}\right)$ is much lower than the load impedance $\left(Z_{L}\right)$.

The resulting symmetrical components when the fault occurs between phases $b-c$ or $c-a$ are given by (15)-(16). It is observed by comparing (14)-(16) that the faulty phases can be detected from the phase angle between $i_{d q h f p c}^{p c}$ and $i_{d q h f p c}^{n c}$. I.e. $\pi / 3$ when the fault occurs between phases $a$ and $b, \pi$ when the fault occurs between phases $b$ and $c$ and $-\pi / 3$ when the fault occurs between phases $a$ and $c$.

$$
\left[\begin{array}{c}
i_{a} \\
i_{b} \\
i_{c}
\end{array}\right]=\left[\begin{array}{c}
\frac{V_{a b}}{Z_{F}} e^{j\left(\left(\omega_{h f}+\omega_{i}\right) t-\pi / 6-\varphi_{Z_{F}}\right)} \\
-\frac{V_{a b}}{Z_{F}} e^{j\left(\left(\omega_{h f}+\omega_{i}\right) t-\pi / 6-\varphi_{Z_{F}}\right)} \\
0
\end{array}\right]+\left[\begin{array}{c}
\frac{V_{a b}}{Z_{F}} e^{j\left(\left(-\omega_{h f}+\omega_{i}\right) t+\pi / 6+\varphi_{Z_{F}}\right)} \\
\frac{V_{a b}}{Z_{F}} e^{j\left(\left(-\omega_{h f}+\omega_{i}\right) t+\pi / 6+\varphi_{Z_{F}}\right)} \\
0
\end{array}\right]
$$$$
\left[\begin{array}{c}
i_{d q h f p c}^{0} \\
i_{d q h f p c}^{c} \\
i_{d q h f p c}^{n c}
\end{array}\right]=\left[\begin{array}{c}
0 \\
\frac{\sqrt{3}}{3} I_{c c} e^{j\left(\left(\omega_{h f}+\omega_{i}\right)-\varphi_{Z_{F}}\right)} \\
\frac{\sqrt{3}}{3} I_{c c} e^{j\left(\left(-\omega_{h f}-\omega_{i}\right)+\pi / 3-\varphi_{Z_{F}}\right)}
\end{array}\right]
$$

$$
\left[\begin{array}{c}
i_{d q h f p c}^{0} \\
i_{d q h f p c}^{p c} \\
i_{d q h f p c}^{n c}
\end{array}\right]=\left[\begin{array}{c}
0 \\
\frac{\sqrt{3}}{3} I_{c c} e^{j\left(\left(\omega_{h f}+\omega_{i}\right) t-\varphi_{Z_{F}}\right)} \\
\frac{\sqrt{3}}{3} I_{c c} e^{j\left(\left(\omega_{h f}+\omega_{i}\right) t+\pi-\varphi_{Z_{F}}\right)}
\end{array}\right]
$$

$$
\left[\begin{array}{c}
i_{d q h f p c}^{0} \\
i_{d q h f p c}^{p c} \\
i_{d q h f p c}^{n c}
\end{array}\right]=\left[\begin{array}{c}
0 \\
\frac{\sqrt{3}}{3} I_{c c} e^{j\left(\left(\omega_{h f}+\omega_{i}\right) t-\varphi_{Z_{F}}\right)} \\
\frac{\sqrt{3}}{3} I_{c c} e^{j\left(\left(\omega_{h f}+\omega_{i}\right) t-\pi / 3-\varphi_{Z_{F}}\right)}
\end{array}\right]
$$

where $I_{c c}=V_{a b} / Z_{F}$.

\section{High frequency signal selection}

Criteria for the selection of the magnitude and frequency of the injected high frequency signal are discussed in this section. 


\section{a) Frequency selection}

For the selection of the frequency, the interaction of the high frequency signal with the output filter resonant frequency, the grid resonant frequency and the need of spectral separation with fundamental frequency dependent harmonics (e.g. $-5^{\text {th }}, 7^{\text {th }} \ldots$ ) that often exist [17-19] need to be considered. It is noted in this regard that for the threephase system case, the frequency of the injected signal can be positive or negative, as it is complex vector. This allows increasing the spectral separation with fundamental frequency dependent harmonics. Frequencies ranging between 75 and $400 \mathrm{~Hz}$ can be found in the literature [9, 1119]. A frequency of $300 \mathrm{~Hz}$ in the stationary reference frame $(250 \mathrm{~Hz}$ in the synchronous reference frame) was chosen both for the simulation and experimental results presented in this paper.

\section{b) Magnitude selection}

Increasing the magnitude of the injected high frequency signal is advantageous for the accuracy (reliability) of the method as it will improve the signal-to-noise ratio. However, increasing the high frequency signal magnitude will increase the THD, therefore being limited by connection standards [1, 2, 4-8].A magnitude of $0.01 \mathrm{pu}$ was selected for the results presented in this paper, as it provided an adequate tradeoff between the reliability of the method and the impact on the THD. It is noted however that the selection of the magnitude might also depend on the selection of the frequency, i.e. larger frequencies might require larger magnitudes, due to the inductive behavior of the system.

\section{Simulation results}

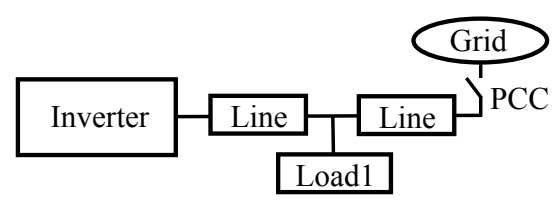

Fig. 7. Simulation scenario for both three and single-phase systems

Fig. 7 shows the scenario used to simulate the proposed islanding and fault detection methods. The same scenario was used for both single-phase and three-phase cases, the corresponding inverter topologies being shown in Fig. 1. The simulation parameters are shown in Table I.

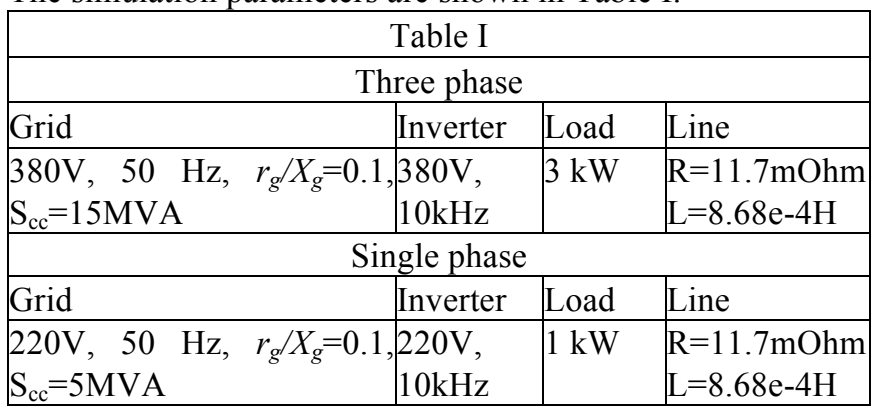

\section{a) Islanding detection}

Fig. 8 shows a transition from island to grid connected for the case of a three-phase system when the pulsating high frequency signal is injected in a stationary reference frame $\left(d q_{s}\right.$, see Fig. 3). Fig. 8a shows the $d q_{s}$ components of the filter output voltage and Fig. $8 \mathrm{~b}$ shows the $d q_{s}$ components
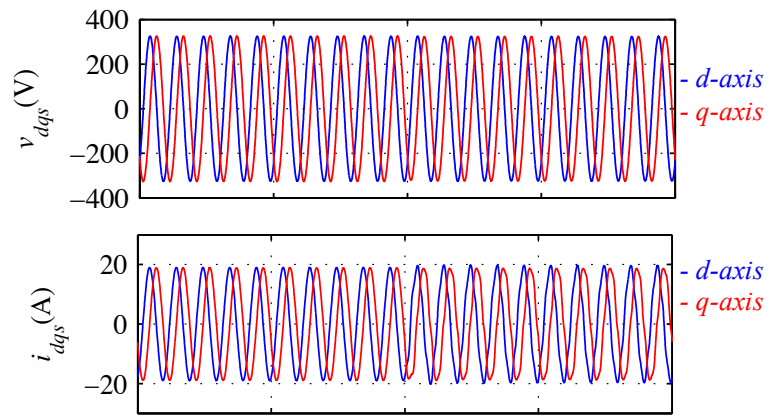

b)

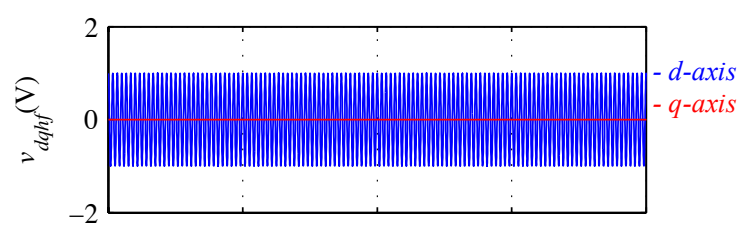

c)

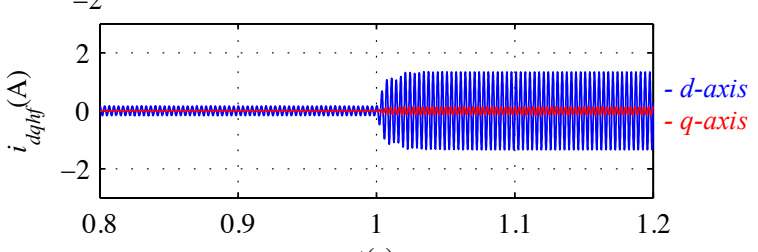

$\mathrm{t}(\mathrm{s})$

Fig. 8 Simulation results. Transition from island to grid connected $(\mathrm{t}=1 \mathrm{~s})$ for the case of three-phase system. a) $d q_{s}$ components of the filter output voltages, b) $d q_{s}$ components of the inverter output currents, c) $d q_{s}$ components of the injected high frequency voltages and d) $d q_{s}$ components of the inverter high frequency currents. $\omega_{h f}=300 \mathrm{~Hz}, V_{h f}=0.01$ pu.

of the inverter output current; Both the voltages and currents shown in Fig. $8 \mathrm{a}$ and $8 \mathrm{~b}$ consist of the fundamental component and the high frequency component, the latest being practically imperceptible due to its reduced amplitude. Fig. 8c shows the $d q_{s}$ components of the injected inverter high frequency voltage after removing the fundamental voltage. Similarly, Fig $8 d$ shows the high frequency components of the inverter output current once the fundamental current has been removed. An increase of the high frequency current magnitude is readily observed after the transition from island to grid connected condition, due to the reduction of the overall high frequency impedance.

Fig. 9 shows the same simulation results as in Fig. 8 for the case of a single-phase system. Fig. 9a and 9b show the inverter output voltage and current respectively (fundamental and high frequency components), while Fig. 9c and 9d shows the corresponding high frequency components. A similar behavior of the inverter output high frequency current is observed, the transition between grid and island modes being readily observed.

Fig. 10 and 11 show the estimated high frequency impedance for three-phase and single-phase systems respectively, when transitions from island to grid and from grid to island occur at $\mathrm{t}=1 \mathrm{~s}$ and $\mathrm{t}=2 \mathrm{~s}$. It is observed that the estimated high frequency impedance is available in a few ms., meeting therefore the islanding detection standards [18]. The THD for the three-phase system when the high frequency signal is not injected is $\approx 1.15 \%$, increasing to $\approx 1.22 \%$ when the high frequency signal is injected. For the single-phase system case, the THD increases from $\approx 1.03 \%$ to $\approx 1.1 \%$ due to the high frequency signal injection. It is 
concluded therefore that injection of the high frequency signal does not compromise connection standards [1, 2, 4-8].

a)
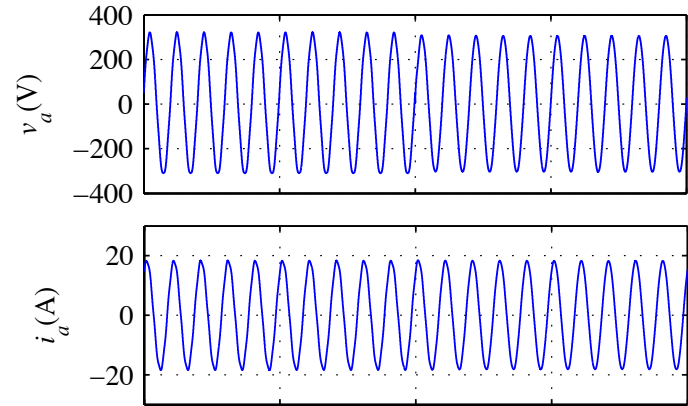

b)

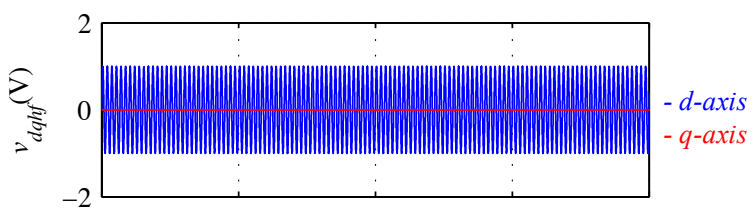

c)

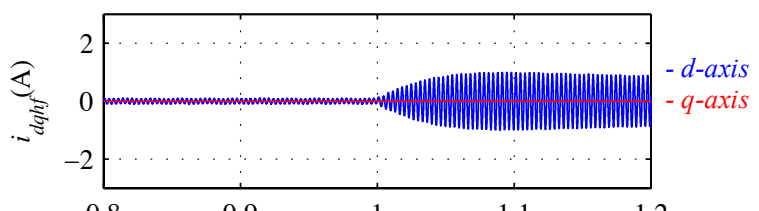

d)

Fig. 9 Simulation results. Transition from island to grid connected ( $\mathrm{t}=1$ s), for the case of a single-phase system. a) Filter output voltage, b) inverter output current, c) $d q_{s}$ components of the injected high frequency voltages, and d) $d q_{s}$ components of the inverter high frequency currents. $\omega_{h f}=300 \mathrm{~Hz}, V_{h f}=0.01 \mathrm{pu}$.

a)
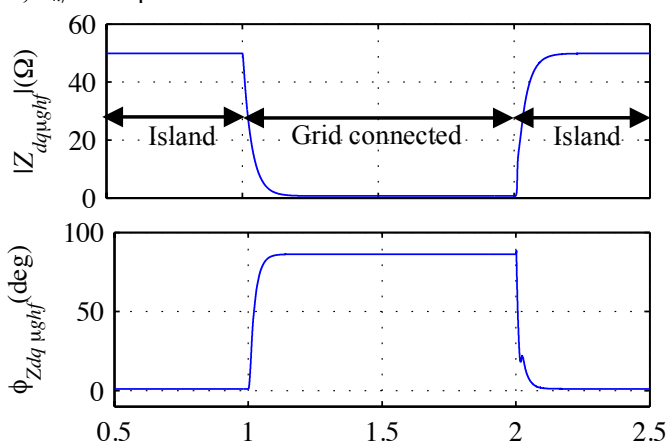

b)

Fig. 10 Simulation results. a) Estimated high frequency impedance magnitude and $b$ ) phase for the case of a three-phase system. Stationary reference frame high frequency signal injection. $\omega_{h f}=300 \mathrm{~Hz}, V_{h f}=0.01 \mathrm{pu}$.
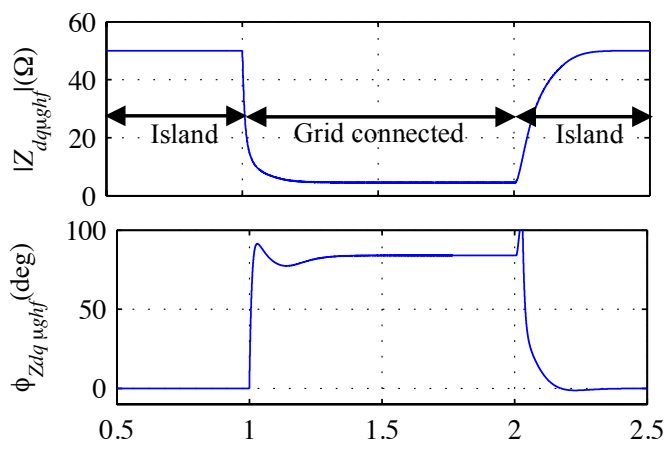

b)

$\mathrm{t}(\mathrm{s})$

Fig. 11 Simulation results. a) Estimated high frequency impedance magnitude and b) phase, for the case of single-phase system. $\omega_{h f}=300 \mathrm{~Hz}$, $V_{h f}=0.01 \mathrm{pu}$.

As already mentioned, the pulsating high frequency signal can be injected either in a stationary or a rotating reference frame in three phase systems. This is confirmed by the results shown in Fig. 12 where grid-island and grid- island transitions are readily observed in the high frequency impedance when the high frequency signal is injected in a rotating reference frame. It is observed from Fig. 8 and 10 that the performance of the pulsating and the rotating high frequency voltage injection methods, [17-19], is very similar. It is noted that a comparative analysis between both methods for the case of single-phase systems is not possible as the rotating high frequency signal injection can only be used with three phase systems [17-19].

a)
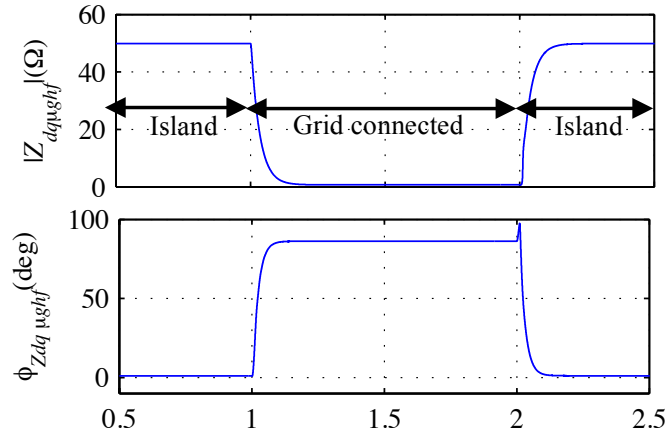

$\begin{array}{cccccc}\text { b) } & 0.5 & 1 & 1.5 & 2 & 2.5 \\ \text { Fig. } 12 & \text { Simulation results. } & \text { a) } & \text { Estimated high frequency impedance }\end{array}$ magnitude and b) phase for the case of a three-phase system when the pulsating high frequency signal is injected in a rotating reference frame. $\omega_{i}=50 \mathrm{~Hz}, \omega_{h f}=300 \mathrm{~Hz}, V_{h f}=0.01 \mathrm{pu}$.

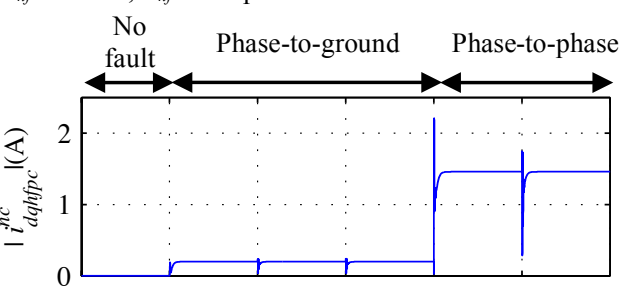

a)

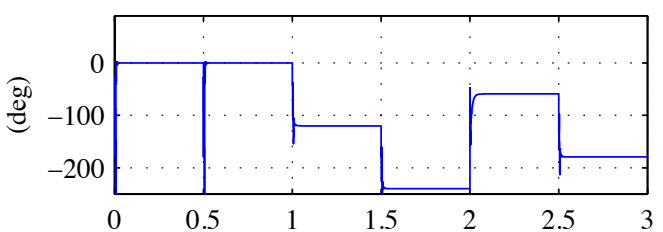

b)

Fig. 13 Simulation results. a) $i_{d q h f p c}^{n c}$ magnitude and b) phase angle between $i_{d q h f p c}^{p c}$ and $i_{d q h f p c}^{n c}$ for the case of a phase-to-ground fault in phase $a$ $(0.5<\mathrm{t}<1 \mathrm{~s}), b(1<\mathrm{t}<1.5 \mathrm{~s})$ and $c(1.5<\mathrm{t}<2 \mathrm{~s})$, and for the case of a phase-tophase fault between phases $a-b(2<\mathrm{t}<2.5 \mathrm{~s})$ and $b-c(2.5<\mathrm{t}<3 \mathrm{~s}) . \omega_{i}=50 \mathrm{~Hz}$, $\omega_{h f}=300 \mathrm{~Hz}, V_{h f}=0.01 \mathrm{pu}$.

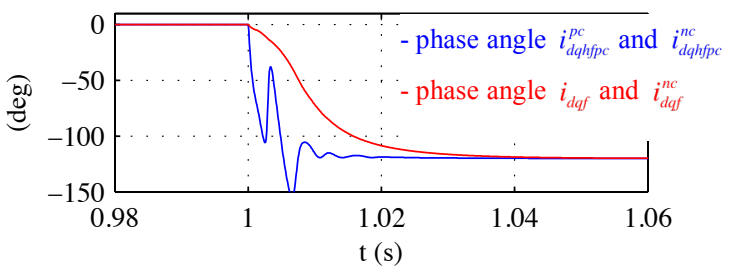

Fig. 14 Simulation results. Phase angle between $i_{d q h f p c}^{p c}$ and $i_{d q h f p c}^{n c}$ and between $i_{\text {daf }}$ and $i_{\text {daf }}^{n c} . \omega_{i}=50 \mathrm{~Hz}, \omega_{h f}=300 \mathrm{~Hz}, V_{h f}=0.01 \mathrm{pu}$.

c) Fault detection

Fig. 13a and 13b show the magnitude of $i_{d q h f p c}^{n c}$ and the phase angle between $i_{d q h f p c}^{p c}$ and $i_{d q h f p c}^{n c}$, for the following faults: phase-to-ground faults in phase $a(0.5<\mathrm{t}<1 \mathrm{~s}), b$ $(1<\mathrm{t}<1.5 \mathrm{~s})$ and $c(1.5<\mathrm{t}<2 \mathrm{~s})$, and phase-to-phase faults between phases $a-b(2<\mathrm{t}<2.5 \mathrm{~s})$ and $b-c(2.5<\mathrm{t}<3 \mathrm{~s})$. It is observed that the magnitude of $i_{d q h f p c}^{n c}$ is zero when there is no fault, the type (phase-to-ground or phase-to-phase) and location or the fault being detected from the phase angle between $i_{d q h f p c}^{p c}$ and $i_{d q h f p c}^{n c}$. 
a)

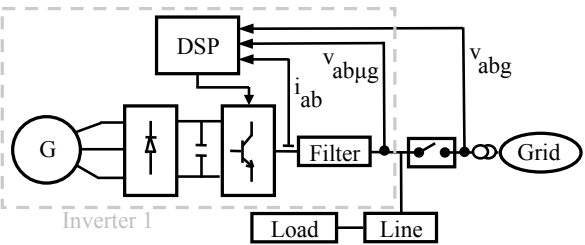

b)

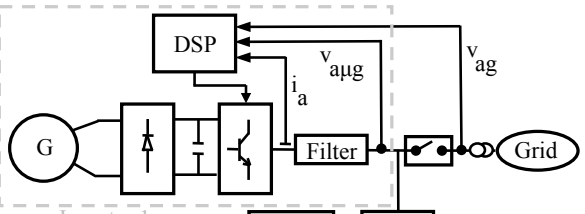

c)

e)

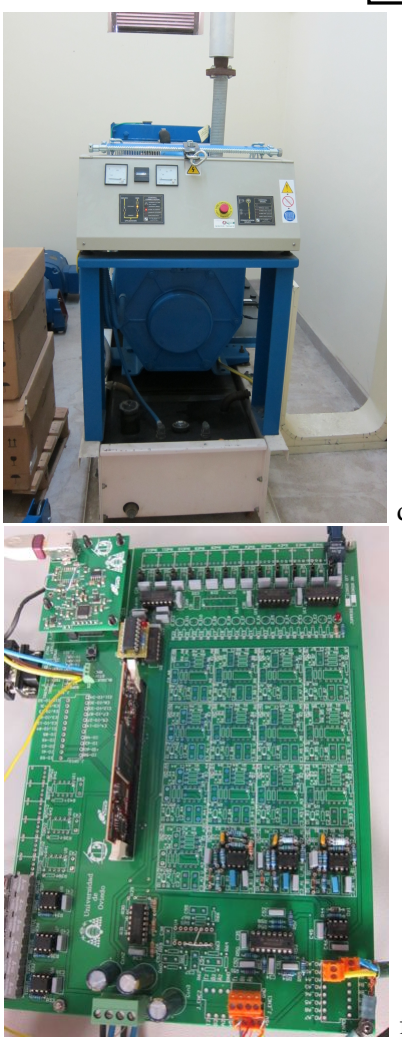

oad Line
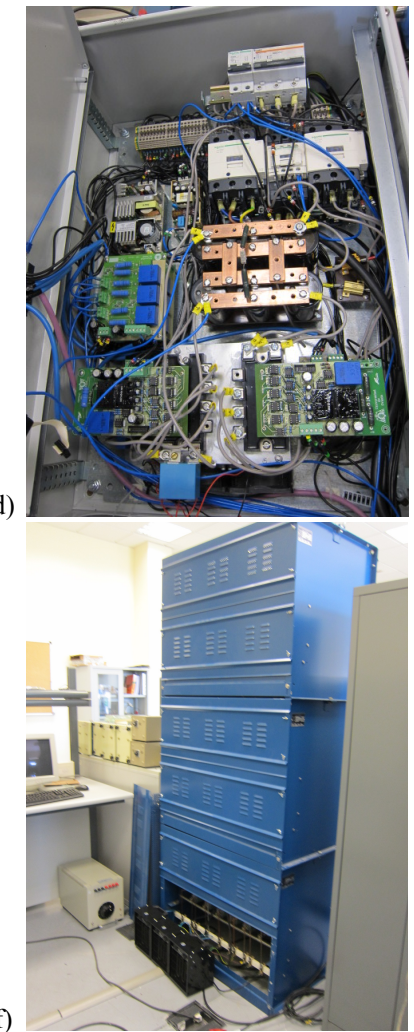

Fig. 15 Experimental setup a) Three-phase and b) single-phase block diagrams c) generator, d) power converter, e) control board and f) Threephase and single-phase loads.

Finally, Fig. 14 shows the dynamic behavior of the angle between positive and negative components of the high frequency current, $i_{d q h f p c}^{p c}$ and $i_{d q h f p c}^{n c}$ (blue), as well as between the positive and negative components of the fundamental current, $i_{d q f}$ and $i_{d q f}^{n c}$ (red), when a phase-toground fault occurs in phase $b(\mathrm{t}=1 \mathrm{~s})$. It is observed that the phase angle between high frequency signals (i.e. $i_{d q h f p c}^{p c}$ and $i_{\text {dqhfoc }}^{n c}$ ) has a faster transient response than that of the fundamental components (i.e. $i_{d q f}$ and $i_{d q f}^{n c}$ ), therefore enabling faster fault detection.

\section{Experimental results}

Fig. $15 \mathrm{a}$ and $15 \mathrm{~b}$ shows the configuration of the experimental setup used both for the case of a three-phase and a single-phase systems. Fig. 15c shows the generator (G in Fig. $15 \mathrm{a}$ and $15 \mathrm{~b}$ ). Fig. $15 \mathrm{~d}$ shows the power converter: rectifier, DC bus, inverter (three-phase and single-phase) and voltage and current measurement. Fig. 15e shows the control board, it uses a DSP TMS320F28335. Fig. 15f shows the three-phase and single-phase loads. The system parameters are shown in Table II.

\begin{tabular}{|c|c|c|c|}
\hline \multicolumn{4}{|c|}{ Table II } \\
\hline \multicolumn{4}{|c|}{ Three phase } \\
\hline Grid & Inverter & Load & Line \\
\hline $\begin{array}{lrl}380 \mathrm{~V}, \quad 50 & \mathrm{~Hz}, \\
\mathrm{~S}_{\mathrm{cc}}=15 \mathrm{MVA}\end{array}$ & $r_{g} / X_{g}=0.1, \begin{array}{l}380 \mathrm{~V} \\
10 \mathrm{kHz}\end{array}$ & $3 \mathrm{~kW}$ & $\mathrm{R}=0.1 \Omega$ \\
\hline \multicolumn{4}{|c|}{ Single phase } \\
\hline Grid & Inverter & Load & Line \\
\hline $\begin{array}{l}220 \mathrm{~V}, \quad 50 \quad \mathrm{~Hz}, \\
\mathrm{~S}_{\mathrm{cc}}=5 \mathrm{MVA}\end{array}$ & $r_{g} / X_{g}=0.1, \begin{array}{l}220 \mathrm{~V}, \\
10 \mathrm{kHz}\end{array}$ & $2 \mathrm{~kW}$ & $\mathrm{R}=0.1 \Omega$ \\
\hline
\end{tabular}

Fig. 16 shows the experimental results for the same grid-island transitions used in Fig. 8 for simulation. As for the simulation results (see Fig. 8), an increase of the high frequency current magnitude is readily observed after the transition from island to grid-connected condition, due to the reduction of the overall high frequency impedance.

a)
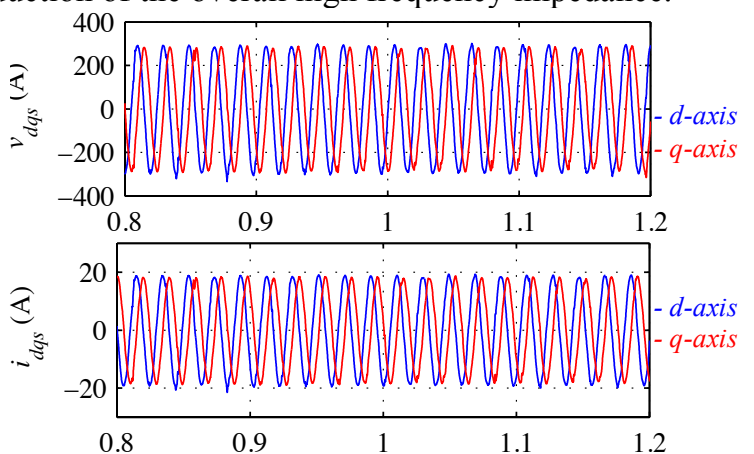

b)

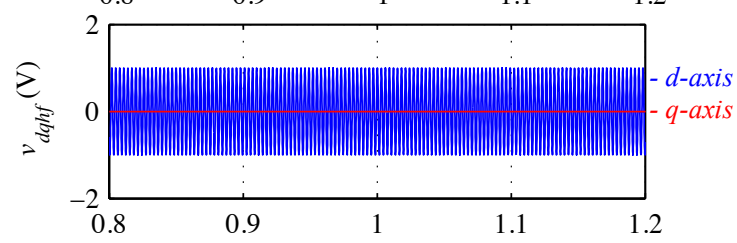

c)

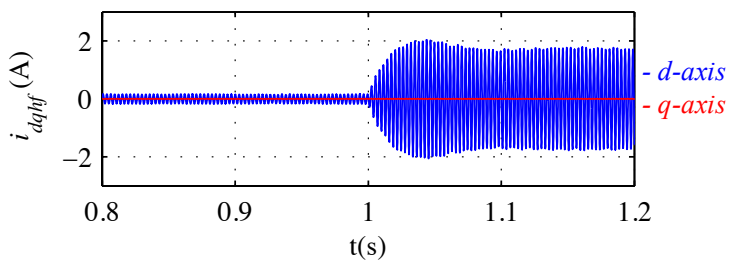

d)

Fig. 16 Experimental results. Transition from island to grid connected $(\mathrm{t}=1 \mathrm{~s})$ for the case of three-phase system. $d q^{s}$ components of a) filter output voltages, b) inverter output currents, c) injected high frequency voltages and d) inverter high frequency currents. $\omega_{h f}=300 \mathrm{~Hz}, V_{h f}=0.01$ pu.

Similarly, Fig. 17 shows the experimental results corresponding to the simulation results in Fig. 9. Again, good agreement between simulation and experimental results is observed.

Fig. 18, 19 and 20 show the magnitude and phase of the estimated high frequency impedance during a transition for island to grid-connected ( $\mathrm{t}=1 \mathrm{~s})$ and from grid-connected to island $(\mathrm{t}=3 \mathrm{~s})$. The high frequency signal was injected in the stationary reference frame in Fig. 18 and in a rotating reference frame in Fig. 19. It is observed that the high frequency impedance change is detected after a few ms. both for the case of three-phase and single-phase systems, therefore meeting the islanding detection standards [1-8]. The total harmonic distortion for the three phase system case 
a)
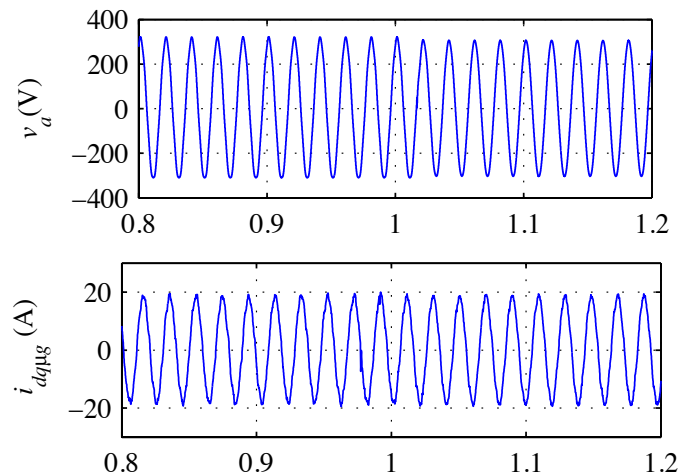

b)

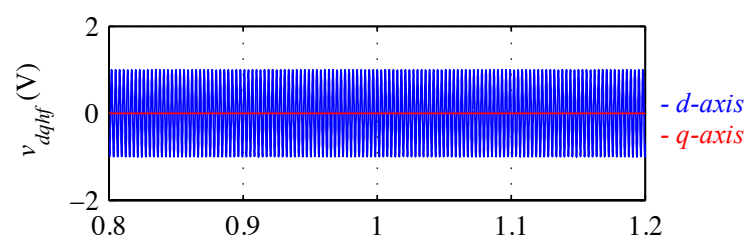

c)

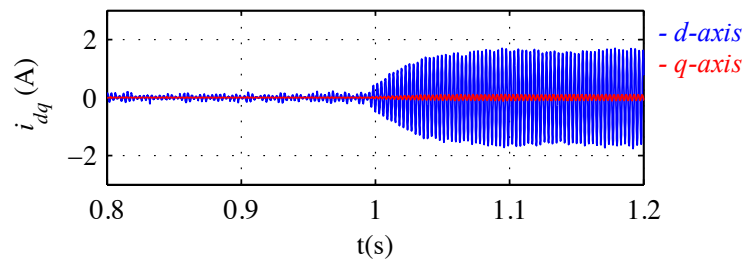

d)

Fig. 17 Experiments results. Transition from island to grid connected $(\mathrm{t}=1 \mathrm{~s})$, for the case of a single-phase system. a) Filter output voltage, b) inverter output current, c) $d q^{s}$ components of the injected high frequency voltages, and d) $d q^{s}$ components of the inverter high frequency currents. $\omega_{h f}=300 \mathrm{~Hz}, V_{h f}=0.01 \mathrm{pu}$.
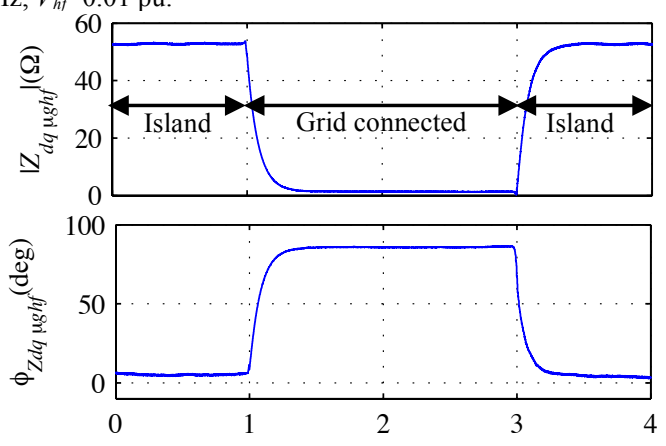

$\mathrm{t}(\mathrm{s})$

Fig. 18 a) Estimated high frequency impedance magnitude and b) phase when the pulsating high frequency signal is injected in the stationary reference frame. $\omega_{h f}=300 \mathrm{~Hz}, V_{h f}=0.01 \mathrm{pu}$.

a)
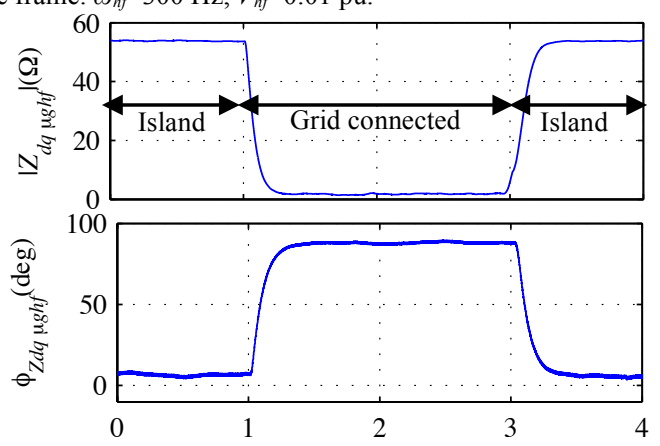

b)

$\mathrm{t}(\mathrm{s})$

Fig. 19 a) Estimated high frequency impedance magnitude, and b) phase when the pulsating high frequency signal is injected in a rotating reference frame. $\omega_{i}=50 \mathrm{~Hz}, \omega_{h f}=300 \mathrm{~Hz}, V_{h f}=0.01 \mathrm{pu}$.

when the high frequency signal is not injected is $\approx 2.72 \%$. Injection of the high frequency signal produces an increase of $\approx 0.09 \%$ (THD $\approx 2.81 \%$ ). For the single-phase system case the THD increases from $\approx 2.64 \%$ to $\approx 2.72 \%$ due to the injection of the high frequency signal. Injection of the high frequency signal does not compromise therefore grid connection standards $[1,2,4-8]$.

a)
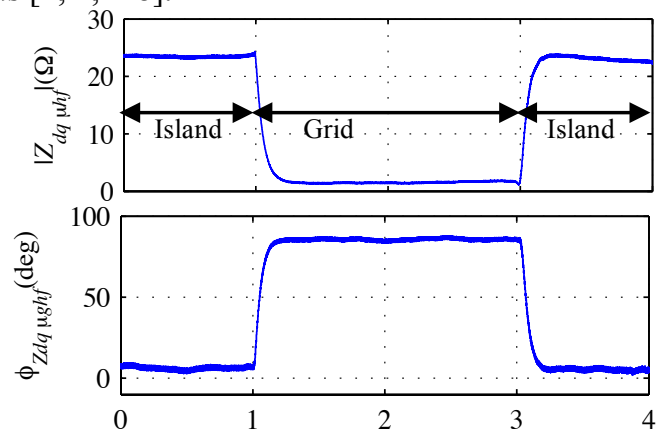

b)

$\mathrm{t}(\mathrm{s})$

Fig. 20 a) Estimated high frequency impedance magnitude and b) phase. Single-phase system. $\omega_{h f}=300 \mathrm{~Hz}, V_{h f}=0.01 \mathrm{pu}$.

a)
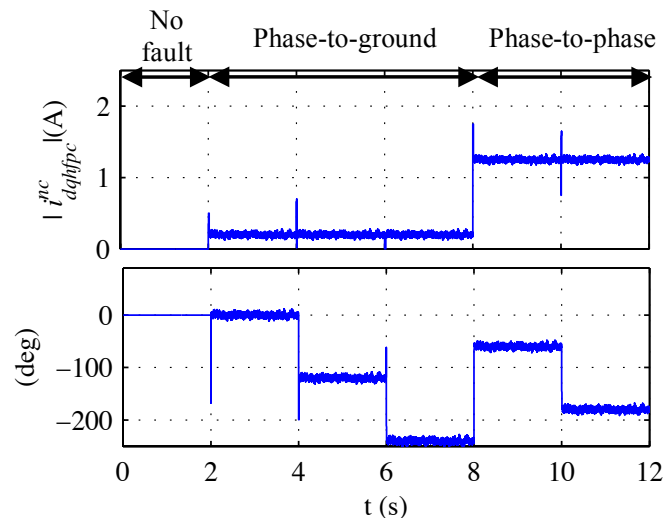

b)

Fig. 21 a) $i_{d q h f p c}^{n c}$ magnitude and b) phase angle between $i_{d q h p c}^{p c}$ and $i_{d q h p c}^{n c}$ for the case of a phase-to-ground fault in phase $a(2<\mathrm{t}<4 \mathrm{~s}), b(4<\mathrm{t}<6 \mathrm{~s})$ and $c(6<\mathrm{t}<8 \mathrm{~s})$, and for the case of a phase-to-phase fault between phases $a-b(8<\mathrm{t}<10 \mathrm{~s})$ and $b-c(10<\mathrm{t}<12 \mathrm{~s}) . \omega_{i}=50 \mathrm{~Hz}, \omega_{h f}=300 \mathrm{~Hz}, V_{h f}=0.01 \mathrm{pu}$.

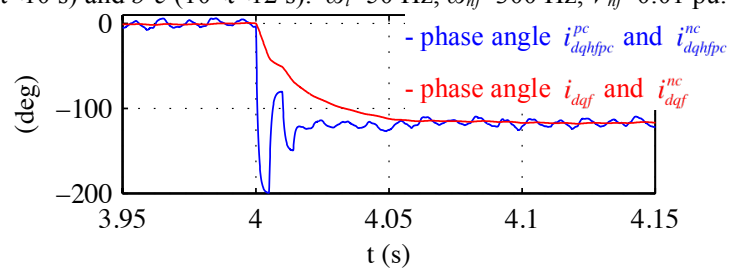

Fig. 22 Phase angle between $i_{\text {dqhfpc }}^{p c}$ and $i_{\text {dqhfpc }}^{n c}$ (blue) and between $i_{d q f}$ and $i_{d d f}^{n c}$ (red) respectively. $\omega_{i}=50 \mathrm{~Hz}, \omega_{h f}=300 \mathrm{~Hz}, V_{h f}=0.01 \mathrm{pu}$.

As in the simulation results, the performance of the pulsating high frequency signal injection method, see Fig. 18 and 19 (experimental results in a three-phase system), and the rotating high frequency voltage injection method [17-19] is very similar.

Fig. 21a and 21b show the magnitude of $i_{d q h f p c}^{n c}$ and the phase angle between $i_{d q h f p c}^{p c}$ and $i_{d q h f p c}^{n c}$, for the following faults: phase-to-ground faults in phase $a(2<\mathrm{t}<4 \mathrm{~s}), b(4<\mathrm{t}<6$ s) and $c(6<\mathrm{t}<8 \mathrm{~s})$, and phase-to-phase faults between phases $a-b(8<\mathrm{t}<10 \mathrm{~s})$ and $b-c(10<\mathrm{t}<12 \mathrm{~s})$. It is observed that the magnitude of $i_{d q h f p c}^{n c}$ is zero when there is no fault, the type of fault being readily detected from the phase angle between $i_{d q h f p c}^{p c}$ and $i_{d q h f p c}^{n c}$. Finally Fig. 22 shows the transient behavior of the phase angle between $i_{d q h f p c}^{p c}$ and $i_{d q h f p c}^{n c}$ (blue) and 
between $i_{d q f}$ and $i_{d q f}^{n c}$ (red), when a phase-to-ground fault occurs in phase $b(\mathrm{t}=4 \mathrm{~s})$ (see description for Fig. 14). In all the cases, it is observed a remarkable agreement with the simulation results shown in Section IV.

\section{Conclusions}

This paper proposes an islanding detection method based on the injection of a pulsating high frequency signal. The method is suitable both for three-phase and single-phase systems. Injection of the pulsating high frequency signal can be performed by any VSI connected to the microgrid. This is an advantage compared to most of already proposed active islanding detection methods based on the estimation of the impedance variation using high frequency signal injection.

It has been shown that injecting a high frequency voltage with a magnitude of $0.01 \mathrm{pu}$ of the line voltage is enough for reliable islanding detection. The THD increase due to the high frequency signal injection is $\approx 0.09 \%$, not compromising therefore connection standards. The island/grid-connected condition is detected in a few ms. both for the three-phase and single-phase systems. This is fast enough to meet the islanding detection standards.

Finally, it has been shown that injection of a pulsating high frequency signal can also be used for unbalance fault detection in three-phase system.

Simulation and experimental results have been provided which confirm the viability of the proposed methods both for islanding and unbalanced operation detection.

\section{References}

[1] IEEE, "IEEE Standard for Interconnecting distributed resources with electric power systems," IEEE Std. 1547, 2003.

[2] UL1741, UL Standard for Safety for Static Converters and Charge Controllers for Use in Photovoltaic Power Systems, Underwriters Laboratories, May 7, 1999, revised June 2001.

[3] IEC 62116, Testing Procedure of Islanding Prevention Measures for Grid Connected Photovoltaic Power Generation Systems, International Electrotechnical Commission.

[4] Australian Standard AS4777, "Grid Connection Of Energy Systems Via Inverters Part 3: Grid Protection Requirements".

[5] IEEE Std. 929-2000, IEEE Recommended Practice for Utility Interface of Photovoltaic (PV) Systems, IEEE Standards Coordinating Committee 21 on Photovoltaics, New York, NY, Apr. 2000.

[6] DIN-VDE, "Automatic Disconnection Device Between a Generator and the Low-Voltage Grid," DIN-VDE Std. 0126-1-1, 2005.

[7] ÖVE/Önorm E 2750 "Photovoltaische Energieerzeugungsanlagen Sicherheitsanforderungen ("Photovoltaic power generating systems safety requirements").

[8] VSE Sonderdruck Abschnitt 12 'Werkvorschriften über die Erstellung von elektr. Installation' Elektrische Energieerzeugungsanlagen Completes VSE 2.8d-95.

[9] F. Briz, D. Reigosa, C. Blanco and J.M. Guerrero, "Coordinated operation of parallel-connected inverters for active islanding detection using high frequency signal injection", IEEE Trans. on Ind. Appl., 50(5): 3476 - 3484, Sept. 2014.

[10] A. Timbus, A. Oudalov, C. N.M. Ho, "Islanding Detection in Smart Grids," IEEE-ECCE'10, pp.3631 - 3637, Sep. 2010.

[11] R. Teodorescu, M. Liserre, P. Rodriguez and F. Blaabjerg, Grid Converters for Photovoltaic and Wind Power Systems, Wiley-IEEE 2011.

[12] M. Ciobotaru, R. Teodorescu, P. Rodriguez, A. Timbus and F. Blaabjerg, "On-line Grid Impedance Estimation for Single Phase GridConnected Systems Using PQ Variations", IEEE-PESC, pp.23062312, June 2007.

[13] A. V. Timbus, R. Teodorescu and U. Borup, "Online Grid Impedance Measurement Suitable for Multiple PV Inverters Running in Parallel", IEEE-APEC'06, pp.907-911, March 2006.

[14] L. Asiminoaei, R. Teodorescu, F. Blaabjerg and U. Borup, "A Digital Controlled PV-Inverter with Grid Impedance Estimation for ENS Detection”, IEEE Trans. on Ind. Appl., 20(6):1480-1490, Nov.-Dec. 2005.

[15] L. Asiminoaei, R. Teodorescu, F. Blaabjerg and U. Borup, "A New Method of On-Line Grid Impedance Estimation for PV Inverter", IEEE-APEC’04, pp.1527-1533, Sept. 2004.
[16] M. Ciobotaru, R. Teodorescu and F. Blaabjerg, "On-line Grid Impedance Estimation Based on Harmonic Injection for GridConnected PV Inverter", IEEE-ISIE, pp.2473-2442, June 2007.

[17] D. Reigosa, F. Briz, C. Blanco, P. Garcia and J. M. Guerrero, "Active Islanding Detection Using High Frequency Signal Injection", IEEE Trans. on Ind. Appl., 48(5):1588-1597, Sept. 2012.

[18] D. Reigosa, F. Briz, C. Blanco, P. García and J. M. Guerrero, "Active Islanding Detection for Multiple Parallel-Connected Inverter-Based Distributed Generators Using High Frequency Signal Injection," IEEE Trans. on Power Elect., 49(3):1411-1420, March 2014.

[19] D. Reigosa, F. Briz, C. Blanco and J. M. Guerrero, "Islanding detection in grid-connected power converters using harmonics due to the non-ideal behavior of the inverter," IEEE-ECCE'13, pp. 26492656, Sept. 2013.

[20] Y. Xue, L. Chang, S.B. Kjaer, J. Bordonau and T. Shimizu, "Topologies of Single-Phase Inverters for Small Distributed Power Generation: An Overview," IEEE Trans. on Power Elect., 15(5):13051314, Sept. 2004.

[21] A. A. Sallam and OM P. Malik, "Electric Distribution Systems," Wiley-IEEE 2011.

[22] Y. Zhou, H. Li, L. Liu, "Integrated Autonomous Voltage Regulation and Islanding Detection for High Penetration PV Applications," IEEE Trans. Power Electr., 28(6): 2826-2841, June 2013.

[23] Y. Zhu, D. Xu, N. He, J. Ma, J. Zhang, Y. Zhang, G. Shen, C. Hu, “A Novel RPV (Reactive-Power-Variation) Antiislanding Method Based on Adapted Reactive Power Perturbation," IEEE Trans. Power Electr., 28(11): 4998-5012, Nov. 2013

[24] A. Yafaoui, B. Wu, S. Kouro, "Improved Active Frequency Drift Antiislanding Detection Method for Grid Connected Photovoltaic Systems," IEEE Trans. Power Electr., 27(5): 2367-2375, May 2012.

[25] X. Chen, Y. Li; "An Islanding Detection Algorithm for Inverter-Based Distributed Generation Based on Reactive Power Control," IEEE Trans. Power Electr., 29(9): 4672-4683, Sep. 2014.

[26] J. Zhang, D. Xu, G. Shen,Y. Zhu, N. He and J. Ma, "An Improved Islanding Detection Method for a Grid-Connected Inverter With Intermittent Bilateral Reactive Power Variation," IEEE Trans. Power Electr., 28(1): 268-278, Jan. 2013.

[27] G.-S. Seo, K.-C. Lee and B.-H. Cho, "A New DC Anti-Islanding Technique of Electrolytic Capacitor-Less Photovoltaic Interface in DC Distribution Systems," Power Electronics, IEEE Trans. Power Electr., 28(4):1632-1641, April 2013.

[28] M. Tedde and K. Smedley, "Anti-Islanding for Three-Phase One-Cycle Control Grid Tied Inverter,” IEEE Trans. Power Electr., 29(7): 33303345, July 2014

[29] S.A. Saleh, A.S. Ajankawey,R. Meng, J. Meng,C.P. Diduch, L. Chang, "Antiislanding Protection Based on Signatures Extracted From the Instantaneous Apparent Power," IEEE Trans. Power Electr., 29(11): 5872-5891, Nov. 2014 